\title{
Modification of Serial Pattern Learning by Designer Tryptamine Exposure during Adolescence: Comparison with Damage to the Dorsal Hippocampus or Prefrontal Cortex
}

\author{
David M. Compton ${ }^{1, *}$, Melissa C. Selinger ${ }^{2}$, Eric Westman ${ }^{1}$, Peter Otero ${ }^{1}$ \\ ${ }^{1}$ Department of Psy chology, Palm Beach Atlantic University, 901 S. Flagler Drive, West Palm Beach, FL 33401, USA \\ ${ }^{2}$ Gregory School of Pharmacy, Palm Beach Atlantic University, 901 S. Flagler Drive, West Palm Beach, FL 33401, USA
}

\begin{abstract}
Foxy or Methoxy Foxy (5-MeO-DIPT) is one of a series of new "club drugs" that within the past decade has gained in popularity among recreational users as an alternative to MDMA (Ecstasy). Unlike MDMA, not much is known about the neurobiological consequences of 5-MeO-DIPT use. Little is known about the effects of either compound on learning in a nonspatial appetitive task. In the present study, adolescent rats were given repeated injections of $10 \mathrm{mg} / \mathrm{kg}$ of 5-MeO-DIPT, MDMA, or a corresponding volume of isotonic saline. In serial learning tasks, depending on task demands, there is a gro wing body of evidence suggesting that multip le memory systems play a critical role, with each system playing a more or less dominant role depending on the available stimuli and task demands. Therefore, for comparison purposes, the drug-treated rats were compared with that of hippocampus- or prefrontal cortex-lesioned rats. After adolescent drug exposure or lesions during adolescence, adult animals were trained All animals were trained for 30 days on a three-element, nonmonotonic pattern consisting of 21, 0 , and 7 food pellets, respectively. Control rats were capable of distinguishing among the elements of the series, as indexed by running times. As expected, the tracking performance of the lesioned rats was impaired. Performance in both the 5-MeO-DIPT- and the MDMA-treated rats improved with training but after 30 days was not markedly different than the lesioned animals. The results are discussed in terms of measured alterations in serotonin activity in the forebrain and the consequences of compro mised serotoninergic systems on the cognitive processes involved in appetitive serial learning tasks.
\end{abstract}

Keywords 5-MeO-DIPT, Fo xy, MDMA, Ecstasy, Serial Learning, Develop ment, Hippocampus, Prefrontal Cortex

\section{Introduction}

Like other mammalian species, rats are capable of tracking the elements of a stimulus series consisting of differing reinforcement quantities[see 1 , for a review]. Although other methods have been employed[e.g., 2], demonstrations of serial learning in rats involves exposure to a three- to seven-element series consisting of differing numbers of food pellets. Anticipatory responding is inferred through the demonstration of different running times to a goal box as a function of the given reinforcement quantity.

While a number of theoretical models have been developed[3], the bulk of the evidence supports the existence of two associative mechanis ms that can explain rodent serial-pattern learning - (1) the development of

* Corresponding author:

david_compton@pba.edu (David M. Compton)

Published online at http://journal.sapub.org/ijpbs

Copyright (C) 2012 Scientific \& Academic Publishing. All Rights Reserved stimulus-stimulus associations[4,5] or (2) the ordinal position of each element of the stimulus series comes to function as a differential cue[6,7]. In a variation of the latter theoretical view, a series of reinforcement events is converted to a spatial array[8].

A consensus has emerged that a hippocampus-dependent memory system, normally labelled as declarative memory, is critical for learning the multiple relationships among stimuli $[9,10]$. This system is considered essential in order for the organism to learn information about and then flexibly utilize information about relationships between multiple external cues and events[9,10]. A second dorsal striatum-dependent system has been described as necessary for the formation of reinforced stimulus-response associations[10-13]. Both systems may be essential for serial learn ing but their relative importance is driven by task requirements[1].

Serial pattern learning involves flexible responding in the face of anticipated changes in the environment. A large body of research has implicated the prefrontal cortex (PFC) 
in many aspects of cognition as well as executive processes[14]. Specifically, the PFC appears to be an essential component in learning and memory, decision making, and cognitive control over behaviour[15-18]. Last, past research has consistently indicated the involvement of the PFC in behavioural flexibility[18-20].

A variety of learning and memory impairments following 3,4-methylenedio xy methamphetamine (MDMA) exposure have been reported in both nonhuman animal studies[21-26] as well as research involving human subjects[27-30]. In humans, MDMA-induced impairments involve a variety of cognitive deficits including alterations in working memory or prospective memory, as well as disruptions in executive functioning[27-30].

Many of the MDMA-induced deficits have been lin ked to observed reductions in brain serotonin (5-HT) levels[31] and this effect has been observed across species (see 32, for a review). Of particular interest here, 5-HT reductions are seen in a number of regions involved in different types of learning and memory, and include such critical brain regions as the hippocampus, the dorsal striatum, and the prefrontal cortices[31]. Further, the effect is observed in adult rats[21] as well as rats exposed when they are young[24-26]. Of considerable import, alterations in 5-HT function have been reported to continue long after the MDMA exposure period[32-36].

As is the case for many other tryptaminergic drugs, 5-Metho xy-N,N-di(iso)propyltryptamine hydrochloride (5-MeO-DIPT; FOXY) has become popular among recreational users. FOXY has properties very similar to that of other tryptaminergic hallucinogens[37]. As a consequence, recreational users of MDMA and other similar compounds have experimented with this drug. However, since it is similar to other tryptamine compounds of abuse, there have been reports of the negative consequences associated with FOXY use as a recreational drug[e.g., 38,39]. As reports of its use accumulated, in the United States FOXY was classified as a Schedule I drug[40]. Although some recent work has elucidated some of the effects of this compound[38-43], unlike MDMA, our knowledge of the consequences associated with the use of FOXY on the behaviour and neurobiology of mammalian systems remains limited.

Adolescence in rats includes the period from the 21st day following birth (postnatal day; PND) until PND 60[44,45]. In addition, adolescence can be subdivided into mid adolescence (PND 34 to 46) and late adolescence (PND 46 to 59). According to Tirelli et al.[45], these two developmental periods are analogous to periadolescence and late adolescence/early adulthood. Rodent models of adolescence models are useful for comparative assessments and for extrapolation to humans [46]. Specifically, the use of adolescent animals allows for a valuable experimental framework for testing the developmental effects associated with drugs of abuse at various time points in biological and cognitive development.
Of the published investigations, only a select few[e.g., 41,43] have specifically examined the effects that FOXY may have on cognition or explored the long-term consequences associated with exposure at different points in brain development. Somewhat more is known about MDMA. However, no one has explored the effects of these compounds on a nonspatial cognitive learning task such as serial pattern learning. Unfortunately, the popularity of these drugs remains high and, as a consequence, the possible risks to development in vulnerable adolescents could be seen as an emerging societal health problem. Therefore, the present study was conducted to provide further elucidation into the consequences of developmental exposure to MDMA and FOXY.

\section{Method}

\subsection{Subjects}

The subjects consisted of 33 male Long-Evans rats (Charles River, Boston, MA) 35 days of age at the beginning of the study. After arrival in the vivarium at 21 days of age, the animals were allowed to acclimate to the facility and were randomly assigned to one of five groups hereafter designated as follows: a control group (CON) consisting of $n$ $=8$ rats, two groups of drug-treated animals exposed to $( \pm)$-3,4-methylenedio xy methamphetamine (MDMA, $n=7$ ) or 5-MeO-DIPT (FOXY, $n=7$ ) and, two lesion groups receiving bilateral lesions of the dorsal hippocampus (HIP, $n$ $=6$ ) or the prefrontal cortex (PFC, $n=5$ ). Four of the eight control rats received sham lesions where the electrode was lowered into the target area but no current was passed.

The rats were individually housed and maintained on a 12-hr light/12-hr dark cycle, with all testing conducted during the light phase. With the exception of serial learning training, the animals were maintained with ad lib access to food and water. The research protocol was reviewed and approved by the Institutional Animal Care and Use Committee of Palm Beach Atlantic University and the animals were treated in accordance with the principles of animal care outlined in the Guide for the Care and Use of Laboratory Animals[47].

\subsection{Apparatus}

The apparatus consisted of a wooden enclosed runway 185 $\mathrm{cm}$ long, $10 \mathrm{~cm}$ wide, and $14 \mathrm{~cm}$ high, with each section covered with hinged Plexiglas. The start and goal boxes (20 $\& 35 \mathrm{~cm}$ in length) were separated from the runway by two manually operated guillotine doors. The start box was painted flat white, the main runway flat grey, and the goal box flat black. Raising a guillotine door located between the start box and the main runway activated one digital timer (Lafayette, Model 20225) which was stopped when the rat interrupted a photobeam located $15 \mathrm{~cm}$ within the goal box. The goal box contained a removable ceramic dish with walls high enough to obscure the food reinforcement until the rat 
was physically inside the goal box. All food reinforcement consisted of a predetermined number of $0.045-\mathrm{g}$ Noyes food pellets. To minimize the presence of odor cues that might have influenced performance[48], the floor of the apparatus was swabbed with a wet sponge and dried with a paper towel before presentation of each element of the series.

\subsection{Behavioural Procedure}

Four days before pretraining began, each rats was weighed and reduced to $85 \%$ of their free-feeding weight. This $15 \%$ reduction was maintained throughout the experiment by feeding a daily maintenance ration (about $14 \mathrm{~g}$ ) of Mazuri Rodent Chow. Water was availab le $a d$ lib.

After the rats' weights were stabilized at the targeted $15 \%$ reduction, a two-day pretraining program began. During this period, individual rats were hand tamed for a two-minute period, followed by a five-minute period where the rats were free to explore the apparatus. Both guillotine doors were elevated during this phase. Last, each rat was permitted to consume 21 food pellets located in the food dish located in the goal box.

Behavioural training began when the rats were approximately 100 days old. Following the two days of pretraining, the experimental training began and continued for 30 days. The rats were transported in their home cages in squads of three animals with the training order randomized daily. All rats received two daily trials consisting of a three-element ordered sequence of 21,0 , and 7 food pellets (Noyes: $0.045-\mathrm{g}$ ). W ithin each three-animal squad, all rats completed trial one before any rat experienced trial two. The intertrial interval was approximately 15 minutes with within-trial inter-element intervals of approximately 1 minute. Once the rat successfully traversed the runway, it was confined in the goal box until all of the food pellets were consumed or for 30 seconds on 0 -pellet elements. When a rat did not reach the goal box within 60 seconds, it was gently pushed toward the goal box, confined there until all food pellets, if any, were consumed, and a 60 second running time was recorded. After consumption of all of the pellets and following each element of the series, the rat was returned to its holding cage while the experimenter swabbed the floor of the apparatus, baited the food-well, and reset the timer and guillotine doors. After the completion of both daily trials, the rats were returned to the rat colony, where they received their maintenance ration of Mazuri Lab Chow not less than 90 minutes later.

\subsection{Surgical Proce dures}

All surgeries were performed under anesthesia consisting of pretreatment with $.25 \mathrm{mg} / \mathrm{kg}$ atropine followed 10 minutes later by $40 \mathrm{mg} / \mathrm{kg}$ of Nembutal. Behavioral pretraining began no less than 10 days following a postoperative recovery period.

Following the appropriate plane of anesthesia, lesions of the dorsal hippocampus were created as follows. Bilateral openings were made in the cranium with a trephine. Electrode placement was determined on the basis of stereotaxic coordinates determined from the atlas of Paxinos and Watson[49]. Following placement of a stainless steel electrode insulated except at the tip, bilateral electrolytic lesions were created in the appropriate site. The coordinates calculated from breg ma and current parameters were AP = $-3.8 \mathrm{~mm}, \mathrm{ML}= \pm 1.5 \mathrm{~mm}, \mathrm{DV}=-3.3 \mathrm{~mm}, 2 \mathrm{~mA}$ for 20 seconds and $\mathrm{AP}=-3.8 \mathrm{~mm} . \mathrm{ML}= \pm 2.5 \mathrm{~mm} . \mathrm{DV}=-3.4 \mathrm{~mm}$ for 20 seconds. Prefrontal cortex ab lations involved removal of areas of the cortex that correspond to those described as the medial precentral, anterior cingulate, and prelimbic cortex as defined by Krettek and Price[50]. Last, as noted earlier, four animals were placed in the stereotaxic device and prepared similarly for lesions, but did not receive lesions (i.e., shams).

\subsection{Histological Analysis \& Biochemical Analysis}

For animals who received lesions, following data collection the subjects were deeply anesthetized (Nembutual, $50 \mathrm{mg} / \mathrm{kg}$ ) and perfused intracardially with $40 \mathrm{~cm}^{3}$ of isotonic saline, followed by a $10 \%$ formalin solution. The brains were removed and stored in a $30 \%$ sucrose- $100 \%$ formalin mixture for 48 hours before being frozen. All brains were sectioned in the coronal plane at $60-\mu \mathrm{m}$ intervals, mounted on slides, and stained with cresyl violet acetate.

HIP lesions were examined under microscopic magnification against stereotaxic atlas templates using the atlas of Paxinos and Watson[49]. Viewed from a dorsal perspective, all cortically ab lated brains were photographed. Subsequent analysis of cortical surface lesions proceeded with a dot grid method[51]. The dot grid method permits placement of a digital grid containing 256 dots per square inch over a Lashley diagram with the accompanied ablation. The number of dots contained within the area of the traced cortical lesion is counted, thus providing an estimate of the amount of cortical surface area destroyed.

Approximately, five weeks after the completion of training on the serial learning task, the animals exposed to MDMA or FOXY were euthanized. Serotonin levels were assessed in a manner described elsewhere[42]. Briefly, we determined 5-HT levels in the hippocampus, striatum, and the prefrontal cortex using high performance liquid chromatography (HPLC; a Waters Model 600 with electrochemical detection). Procedures were consistent with that outlined by Chapin, Lookingland, and Moore[52] with modification. The system used a Waters $\mathrm{C}_{18}$ reverse phase analytical co lu mn ( 3.9 X $300 \mathrm{~mm} ; 4 \mu \mathrm{m})$. Concentrations in the amounts of $0.04 \%$ sodium octyl sulfate, $0.1 \mathrm{mM}$ disodiumethylenediamine-tetraacetate, $0.05 \mathrm{M}$ sodium phosphate were dissolved in laboratory-grade H20 using $0.03 \mathrm{M}$ citric acid as a buffer. The aqueous portion of the mobile phase was held within $\mathrm{pH}$ levels between 2.7 and 2.9. The mobile phase consisted of $20 \%$ methanol and $80 \%$ aqueous phase. 5-HT levels were calculated and reported as $n g / g$ tissue. 
Table 1. Mean levels of 5-HT in the hippocampus, prefrontal cortex, and striat um of NaCl-, MDMA, or FOXY-treated rats

\begin{tabular}{cccc}
\hline Drug Group & Hippocampus & Prefrontal Cortex & Striatum \\
& $M(S D)$ & $M(S D)$ & $190.25(18.11)$ \\
NaCl-Treated Rats & $130.51(19.96)$ & $140.41(20.91)$ & $115.60(19.55)^{*}$ \\
MDMA-Treated Rats & & & -39.24 \\
\%Reduction & $47.43(5.66)^{*}$ & $45.13(16.88)^{*}$ & $128.48(23.39)^{*}$ \\
\%eO-DIPT-Treated Rats & -63.66 & -67.85 & -32.47 \\
\hline
\end{tabular}

Notes. All measurements are in $n g / g$. *significantly different from $\mathrm{NaCl}(\mathrm{CON})$ group $(p<.05)$

\subsection{Data Analysis}

In order to normalize the data, the running times were transformed using the reciprocal $(X=1 / X)$ data transformation[53]. The data were collapsed into three blocks consisting of days 1through 6, 7 through 18, and 19 through 30, respectively and were analyzed, using a three-way ANOVA: 3 (groups) x 3 (blocks) x 4 (elements). We treated groups as a between-subjects factor, whereas blocks and elements were treated as within-subject factors. We used TukeyнsD tests to analyze the within-group differences in running times to the series elements.

\section{Results}

\subsection{Histological Analysis}

Visual examination of the HIP-lesioned animals revealed the following (see Figure 1). Substantial damage to the overlying cortex, corpus callosum, and cingulum was seen in all animals as was considerable damage to the fimbria. All animals had minor damage to the laterodorsal area of the thalamus and the stria terminalis. One animal received minor da mage to the anterodorsal region of the thalamus. In addition, extra-hippocampal structures with minor damage included the dorsal lateral geniculate nucleus (one animal), the anterior pretectal nucleus (one animal), and the paraventricular nucleus (one animal).

Examination of the PFC lesions indicated that they generally involved the area fro $m$ the frontal pole to the genu of the corpus callosum. With the exception of one rat, the tissue along the medial wall of the medial walls of the saggital sulcus, including the majority of the cingulate gyrus, was undamaged. Conversely, some involvement of the anterior cingulate gyrus was found in all five animals. Using the dot grid method described previously, suggested that when the lesions were considered from the dorsal perspective that they were uniform in size $(M=0.21, S D=$ 0.013).

\subsection{Neur ochemical Anal ysis of Brain 5-HT Levels}

The mean levels of 5-HT in the hippocampus, prefrontal cortex, and striatum are reported in Table 1. The 5-HT levels differed as a function of drug exposure in each measured area (hippocampus, $F(2,19)=60.94, p<.001$; prefrontal cortex, $F(2,19)=59.68, p<.001$; striatum, $F(2,19)=29.29, p$ $<.001$. Post hoc examination of these results using Tukey ${ }_{\mathrm{HSD}}$ tests revealed the following differences among groups. When compared to the $\mathrm{CON}$ ( $\mathrm{NaCl}$-treated) animals, an examination of the 5-HT levels in the hippocampus indicated significant reductions in 5-HT (63.66\% \& 50.11\%) in both the MDMA and FOXY drug groups. However, when the two drug groups were compared, the 5-HT levels were comparable (i.e., $p>.05$ ).

Reductions in prefrontal 5-HT levels were observed in both the MDMA-treated rats (67.85\%) and the FOXY-treated rats $(60.57 \%)$. However, the difference in 5-HT levels in both drug-treated groups was nonsignificant. Last, when compared to control animals, significant reductions in striatal 5-HT were also observed (39.24\% for MDMA \& $32.47 \%$ for the FOXY rats). The pattern of differences between the CON group and two drug groups but not the two drug groups as measured 5-HT levels in these target areas is consistent with previous work[42].

\subsection{Behavioural}

The goals of the present investigation were to determine (1) if prior exposure of MDMA or FOXY disrupted the ability of rodents to learn a nonmonotonic serial pattern and (2) compare the results to that of hippocampal or PFC lesioned rats. Therefore, learning performance was considered at points within the 30 days of training. To do this, the data were collapsed into three blocks consisting of days 1 through 6, 7 through 18, and 19 through 30. In order to meet the assumptions associated with the analysis of variance (ANOVA), all running times were transformed using the reciprocal transformation.

The serial learning performance of each group collapsed into the three training period blocks is presented in Figure 2. A one between (drug or lesion groups), two-between (blocks \& elements) ANOVA revealed the following. A main effect of group was found, $F(4,28)=6.71, p<.01$, indicat ing that running times differed across the training period. As the 
main effect of blocks, $F(2,56)=64.25, p<.05$, suggests, the animals improved across the training period and running times differed, $F(2,56)=74.57, p<.05$, as a function of run within the three-element series. The group $\mathrm{X}$ blocks and group $\mathrm{x}$ elements interactions were both significant as well $(F s(8,56)=3.30 \& 8.96, p s<.01$, respectively $)$. Here, the results suggest that group differences emerged both across the three blocks associated with the early, middle, and late training periods as well as within individual elements of the series.

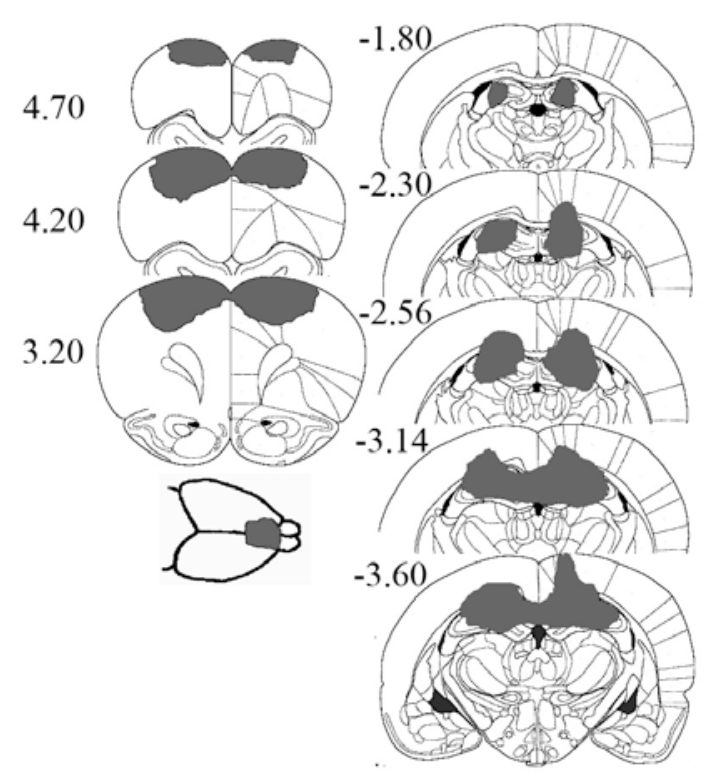

Figure 1. Representative PFC and HIP lesions. Numbers are relative to bregma as defined by Paxinos and Watson[49]

However, the results must be interpreted in light of the significant group $\mathrm{xb}$ locks $\mathrm{X}$ elements interaction, $F(16,112)$ $=3.19, p<.01$. To assess the tracking ability of each group, the three-way interaction was decomposed using post hoc tests for repeated measures $(p<.05)$. Within the three-element series, accurate tracking was defined as differential running times to each element of the series in anticipation of each quantity of reinforcement[54]. That is, accurate tracking of the elements of the series involved running significantly more slowly to the 0-pellet element than to the two rewarded elements of the series, and significantly more slowly to the 7 - than to the 21-pellet element.

For the control group, differences among the elements of the series first appeared in the second block of training with the rats running faster to the 21 - than the 0 -pellet element. As reflected in their running times, by the third block of training the control animals were able to distinguish between all three elements of the series.

HIP-lesioned animals were able to distinguish between the 21-pellet and 0-pellet elements by the second block of training and between the 21-pellet and the other two elements of the series by the last block of training. However, unlike the control animals, the performance of HIP-lesioned animals was impaired on the second and third elements of the series $(p s>.05)$. PFC-lesioned animals performed worse with significant differences in running times only detected on the 21- and 7-pellet elements in block three of training.

Examination of the animals exposed to the drugs in adolescence revealed the fo llowing. MDMA animals showed little evidence of tracking throughout training until the third block. However, in the third block of training, the rats did have significantly lower running times to the 21-pellet element but only when it was compared with the 7-pellet element. The running times to the 0-pellet element were significantly faster than to the 7-pellet element but did not differ from the 21-pellet element of the series. The worst tracking performance of all was observed among the animals exposed in adolescence to FOXY. These animals were unable to distinguish among the elements of the series (see Figure 2).

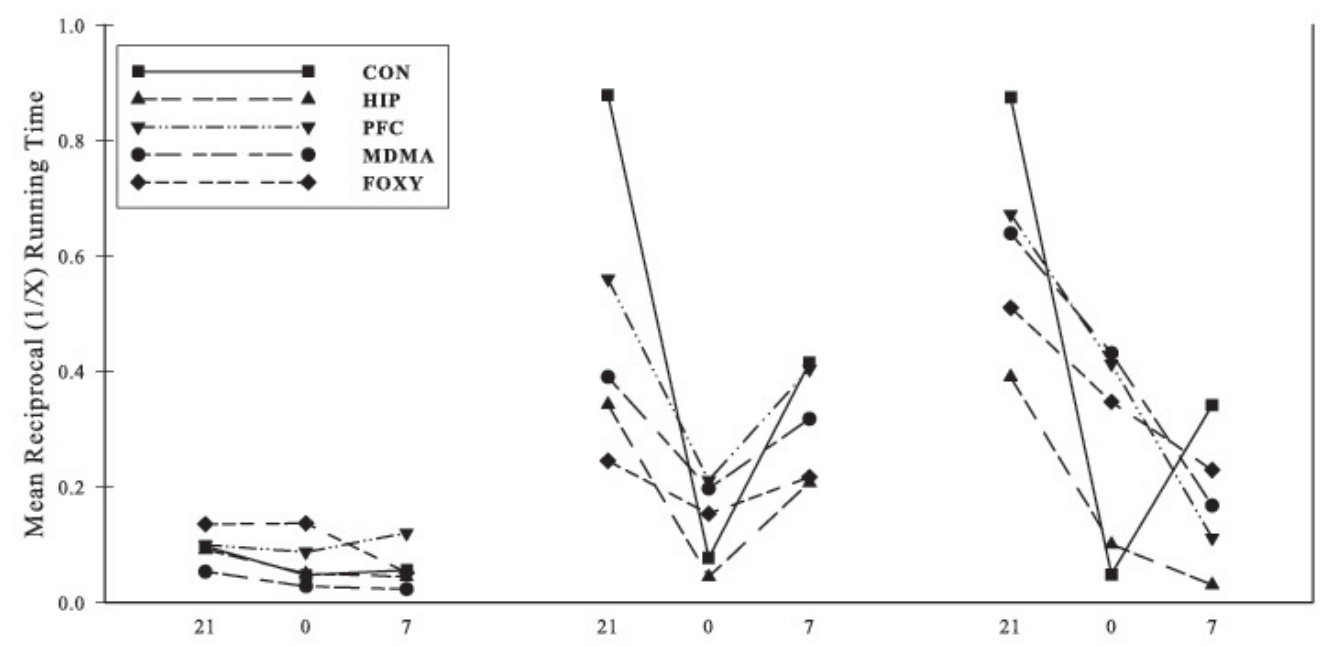

Figure 2. Mean reciprocal running times in three blocks consisting of days 1 through 6,7 through 18 , and 19 through 30 , respect ively 
Additional confirmation of the observed lesion and drug associated deficits through the use of regression analyses. Figure 3 illustrates the linear relationship between the quantity of reinforcement and the block three running times used in the previous analysis. In comparison with the other groups, the control rats demonstrated high levels of anticipatory responding, $R^{2}=.730, F(1,22)=59.44 . p<.001$. Consistent with the previous section, anticipatory tracking performance was impaired in both lesion groups, with PFC rats displaying a more significant impairment $\left(R^{2} \mathrm{~s}=.578\right.$ \& .218, HIPs \& PFCs, respectively). When the adolescent-treated drug rats were considered, similar impairments consistent with above were observed $R^{2} \mathrm{~s}=.221$ \&.108, MDMA- \& FOXY-treated rats, respectively). In fact, the amount of variance in running times observed in the FOXY-treat rats, $10.8 \%$, was nonsignificant. Last, trend analyses revealed that, with the exception of the control group, a quadratic equation provided the best fit of the data when the elements considered in their order within the series. Conversely, a linear equation provided the best fit of the data for the remaining groups where the third element of the series, 7 pellets, was associated with the slowest running times.
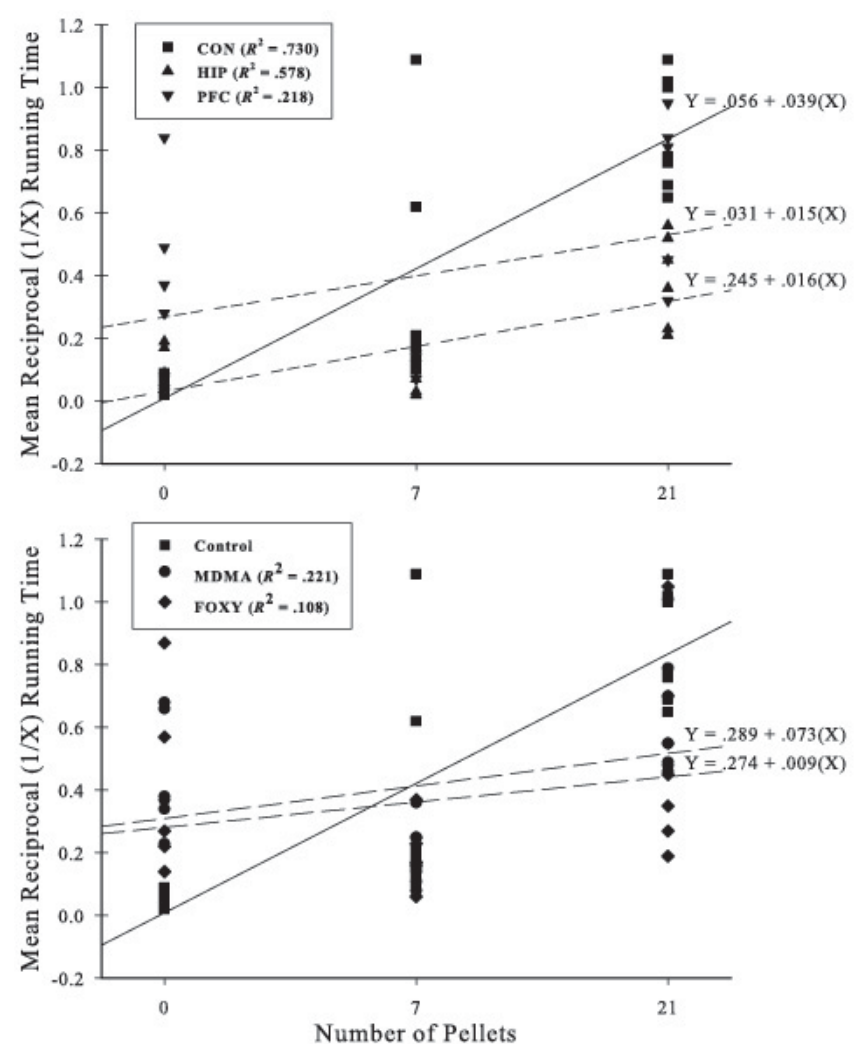

Figure 3. Mean reciprocal running times in three blocks consist ing of days 1 through 6,7 through 18 , and 19 through 30 , respectively

As Botwinick[55] noted, when considering instrumental learning tasks, motor deficits can impact the results, suggesting a cognitive impairment when the changes are not related to alterations in cognition[56]. To potentially rule this out, the data from the last block were collapsed and the groups compared. This analysis yielded a significant effect of group, $F(4,28)=3.90, p<.05$. However, post hoc comparison of each group versus the control group (Dunnett, two-tailed) revealed only a significant difference between the control animals and the HIP-lesioned animals. Thus, although not unequivocal, the results suggest that the groups were capable of similar running speeds.

\section{Discussion}

The purpose of the present experiment was to examine the impact of adolescent exposure of MDMA and FOXY on the acquisition of appetitive serial learning task. A second goal was to compare the performance of the drug-treated rats with that of HIP- and PFC-lesioned animals, two regions implicated in serial pattern learning[1] and processes such as rule-learning and response flexibility[57]. Exposure to either drug during adolescence produced a marked learning impairment in the serial learning task in (drug-free) adulthood. The deficits were as severe as that of the brain lesioned groups, with the performance of the drug-treated animals all but indistinguishable from that of the PFC animals. Only the CON animals demonstrated accurate tracking performance. In related work[42], no differences in performance on the rotating balance beam or in levels of general activity have been found suggesting that the deficits were not simply a result of motor deficits.

There is a growing body of evidence suggesting that multiple brain areas are involved in sequential learning and memory[58]. In humans, this is supported from work with drug-treated[59] or brain damaged individuals on serial reaction time tasks[60,61]. The work of Nissen and colleagues supported the proposal that serial learning involves activity within both declarative and nondeclarative (procedural) memory systems[59,60; see also, 62]. Individuals with Alzheimer's disease or experimental participants treated with the acetylcholine antagonist scopolamine improved across trials with a 10-element sequence but had no explicit recognition for the learning experience[59,60]. As such, the results suggested that serial learning relies on a nondeclarative memory system. Conversely, Huntington's disease patients, with a compromised nondeclarative memory system that includes but is not limited to the basal ganglia showed no improvement. Last, much like Huntington's patients, individuals with Parkinson's disease have sequence learning deficits that are independent of more general impairments in motor performance[58,63,64].

As Muller \& Fountain[58] noted, the available evidence suggests that rats may rely on at least three cognitive processes in serial pattern learning. The use of memory for items in a series may involve any combination of (1) the processing of external discriminative cues, (2) counting time encoding processes for each position of the elements of the series and/or, abstraction of a rule or rules for encoding an 
internal representation of the structure of the pattern[58].

Consistent with the earlier discussion, in rats mastery of an appetitive serial-pattern learn ing task is influenced by at least two dissociable neural systems. First, animals are capable of learning the serial pattern using a declarative memory system that includes the hippocampus, incorporating stimulus-stim ulus and rule learning $[1,58,65]$. If this system is compromised or if the salience of stimulus elements is skewed, then a nondeclarative memory system that includes the dorsalstriatum willpermit the rat to learn the series[1]. In fact, the nondeclarative system appears to drive the formation of reinforced S-R responses, with a third system that includes the amygdala appearing to contribute to the affective aspects of the experience[66-69). Which neural system is dominant is largely determined by the stimuli available to predict a given trial outcome and the complexity of the specific serial pattern[1].

The prefrontal cortex is one of a number of critical brain regions that are involved in the ability to respond in an effective manner when confronted with changing contingencies between a stimulus and response[15,70]. In serial pattern learning, such flexibility is critical as contingencies (trials) change. Indeed, there is evidence that depletion of prefrontal/orbitofrontal 5-HT is highly correlated with the perseverative impairments [71,72].

Further, experimental manipulations of 5-HT levels in the cerebral cortex leading to lower 5-HT levels are associated with an enduring increase in response impulsivity[62]. In the present experiment, determination of whether the observed deficits were a result of cognitive flexibility or other processes, or both is not readily determined. As noted earlier, rodent serial learning involves multiple brain structures and multiple learning strategies that differ depending on task demands[1,58]. Last, it has been observed that genetic variations in the monoaminergic transporter protein SERT impact cognitive flexibility[73]. Reductions in SERT binding following MDMA exposure are considered indicative of serotonergic axonal damage[74].

In the present study, FOXY-treated rats were impaired relative to CON animals with the impairment approaching that of MDMA-treated rats. Although generally the effects of the former do not appear to be as severe as the latter[43,75], neither appear to diminish with age[42]. In a related study, we compared adolescent exposure of FOXY with MDMA and periodically tested the animals across the lifespan with the preliminary results indicating that the deficits largely remain throughout the lifespan[76].

In one recent investigation[43], rats treated with FOXY during postnatal day 11-20 were impaired relative to control animals in spatial learning but not tests of spatial memory or path integration. However, in related work with adult rats[77], a path integration deficit was observed. Of relevance here, the authors suggest that the difference is possibly a reflection of hippocampal development[c.f., 78] that occurs during the exposure period used in their study.

When considering factors such as exposure to drugs of abuse, the period of exposure during biological development is a relevant variable[43]. For example, in one study of 5-HT turnover in the nucleus accumbens of rats[79], levels of 5-HT turnover in the nucleus accumbens were four times lower in adolescent rats than prepubescent rats (PND 10 to 15 ) or adult rats. Further, in rodents, 5-HT2A receptor in the cortex is at its peak just before the onset of adolescence, followed by a gradual decline to adult levels[80]. Thus, the timing of exposure of each of the compounds could have a variety of effects that differ markedly depending on when exposure takes place during neural development, what other drugs are taken concurrently, and the length of exposure.

Data fro mthe neurochemical ass essment of 5-HT revealed substantial reduction in 5-HT levels measured in the prefrontal cortex, hippocampus, and the striatum. This result is largely in accord with previous research with rats $[41-43,75,76]$ and mice[81]. As noted above, the timing of exposure is important, with some reports suggesting more persistent 5-HT reductions if the drug exposure period includes early adolescence rather than during a later developmental period[81]. In addition, multiple doses of MDMA can produce measurable 5-HT toxicity in periods greater than 100 days following exposure[82]. Nonetheless, the available evidence is mixed as there are some reports of an absence in the reduction of 5-HT levels following adolescent exposure[83] and some species differences (rats vs. mice) have been observed $[82,84,85]$.

One additional caveat concerning the present results is noteworthy. While significant reductions in 5-HT levels were detected after exposure to both MDMA and FOXY, lin king 5-HT levels with that of neurotoxicity is still an area of debate[74]. This is true even if measured using different methods, including the methods employed here and elsewhere[43,74] and radioligand binding in SERT studies[86,87]. While the issue cannot be settled here, excellent discussions of the issues can be found in the literature[88-90]. At any rate, regardless of whether the drug-induced deficits were related to axonal damage or another process, on a functional level the animals were impaired when tested as adults, long after adolescent exposure and is consistent with previous reports[42,43].

The present study lends additional support to the suggestion that there is a developmental period of vulnerability to the effects of both MDMA and FOXY. Perusal of recommendations on the internet[e.g., 91,92] suggest that concurrent use of selective serotonin reuptake inhibitors with MDMA can ameliorate or even prevent the adverse side effects or even damage caused by MDMA[74]. In the present study as well as reports by others $[42,43]$, exposure to MDMA and FOXY appear to produce lasting consequences. Since other neurotransmitter systems (e.g., dopamine, norepinephrine) may be compromised by the use of these compounds as well[43,74,75,93,94], it is imperative in future research to examine the behavioural consequences in youth who use such drugs for recreational purposes. By doing so, more effective ameliorative and therapeutic strategies can be developed. 


\section{ACKNOWLEDGEMENTS}

This research was sponsored in part by a grant from the Palm Beach Atlantic University Faculty Research Committee to David Compton. The authors would like to thank N. Hernandez and K. Dietrich for their expert technical assistance.

\section{REFERENCES}

[1] Compton, D. M. (2001). Are memories for stimulus-stimulus associations or stimulus-response associations responsible for serial-pattern learning in rats? Physiology \& Behavior, 72, 643-652. doi:10.1016/S0031-9384(01)00429-2

[2] Fountain, S. B., Rowan, J. D., \& Carman, H. M. (2007). Encoding structural ambiguity in rat serial pattern: The role of phrasing. International Journal of Comparative Psychology, 20, 25-34.

[3] Capaldi, E. J., \& Miller, R. M. (2004). Serial learning in rats: A test of three hyp otheses. Learning \& Motivation, 35, 7181. doi:10.1016/S0023-9690(03)00043-2

[4] Capaldi , E. J. (1985). Anticipation and remote associations: A configural approach. Journal of Experimental Psychology: Learning, Memory, and Cognition, 11, 444-449. doi:10.1037//0278-7393.11.3.444

[5] Capaldi, E. J., Alptekin, S., Miller, D. J., \& Birmingham, K. M. (1997). Is discriminative responding in reward outcome serial learning mediated by item memories or position cues? Learning and Motivation, 28, 153-169. doi:10.1006/lmot. 1996.0964

[6] Burns, R. A., Dunkman, J. A., Jr., \& Detloff, S. L. (1999). Ordinal position in the serial learning of rats. Animal Learning \& Behavior, 27, 272-279. doi:10.3758/BF03199725

[7] Burns, R. A., Hulbert, L. G., \& Cribb, D. (1990). A test for order relevance in a three-element serial learning task. Journal of General Psychology, 117, 91-98. doi:10.1080/ 00221309.1990.9917776

[8] D'Amato, M. R., \& Columbo, M. (1988). Representation of serial order in monkeys (Cebus appella). Journal of Experimental Psychology: Animal Behavior Processes, 14, 131-139. doi:10.1037//0097-7403.14.2.131

[9] Cohen, N.J., \& Eichenbaum, H., 1993. Memory, amnesia, and the hippocampus. Cambridge, MA: MIT Press.

[10] Kesner, R. P., \& Rogers, J. (2004). An analysis of independence and interactions of brain substrates that subserve multiple attributes, memory systems, and underly ing processes. Neurobiology of Learning and Memory, 82, 199-215. doi:10.1016/j.nlm.2004.05.007

[11] Mishkin, M., \& Petri, H. L. (1984) Memories and habits: Some implications for the analyses of learning and retention. In L. R. Squire \& N. Butters (Eds.), Neuropsychology of Memory pp. 287-296. New York: Guilford.

[12] Packard, M. G. (2008). Neurobiology of procedural learning in animals. In H. Eichenbaum (Ed.), Learning and memory: $A$ comprehensive reference (Vol. 3), pp. 341-356. San Diego,
CA: Academic Press.

[13] Packard, M. G. (2010). Role of basal gan glia in habit learning and memory: Rats, monkeys, and humans. In H. Steiner \& K. Y. Tseng (Eds.), Handbook of behavioral neuroscience (Vol. 20), pp. 561-569. Oxford, UK: Elsevier.

[14] Ranganath, C., \& Blumenfeld, R. S. (2008). Prefrontal cortex and memory. In H. Eichenbaum (Ed.), Learning and memory: A comprehensive reference (Vol. 3), pp. 261-279. San Diego, CA: Academic Press.

[15] Dalley, J. W., Cardinal, R. N., \& Robbins, T.W. (2004). Prefrontal executive and cognitive functions in rodents: neural and neurochemical substrates. Neuroscience and Biobehavioral Reviews, 28, 771-784. doi:10.1016/j.neubiore v.2004.09.006

[16] Goldman-Rakic, P. S. (1996). The prefrontal landscape: implication of functional architecture for understanding human mentation and the central executive. Philosophical Transactions of the Royal Society B: Biological Sciences, 351, 445-453. doi:10.1098/rstb.1996.0129

[17] Miller, E .K. (2000). The prefrontal cortex and cognitive control. Nature Reviews Neuroscience, 1, 59-65. doi:10.1038/ 35036228

[18] Robbins, T. W., \& Crockett, M. J. (2010). Role of central serotonin in impulsivity and compulsivity: Comparative studies in experimental animals and humans. In C. P. Müller \& B. L. Jacobs (Eds.), Handbook of the behavioral neurobiology of serotonin pp. 415-427. San Diego, CA: Academic Press.

[19] Del'Guidice, T., Nivet, E., Escoffier, G., Baril, N., Carverni, J.-P., \& Roman, F. S. (2009). Perseveration related to frontal lesion in mice using the olfactory H-maze. Behavioural Brain Research, 205, 226-233. doi:10.1016/j.bbr.2009.08.007

[20] Kolb B. (1990). Prefrontal cortex. In B. Kolb \& R. C. Tees (Eds.). The cerebral cortex of the rat pp. 437-458. Cambridge, MA: MIT Press.

[21] Able, J. A., Gudelsky, G. A., Vorhees, C. V., \& Williams, M. T. (2006). 3,4-M ethy lenedioxymethamp hetamine in adult rats produces deficits in path integration and spatial reference memory. Biological Psychiatry, 59, 1219-1226. doi:10.1016/ j.biopsych.2005.09.006.

[22] Arias-Cavieres, A., Rozas, C., Rey es-Parada, M., Barrera, N., Pancetti, F., Loy ola, S., Lorca, R. A., Zeise, M. L., \& Morales, B. (2010). MDM A (“ecstasy”) impairs learning in the Morris Water Maze and reduces hippocampal LTP in young rats. Neuroscience Letters, 469, 375-379. doi:10.1016/j.neulet. 2009.12.031

[23] Sprague, J. E., Preston, A. S., Leifheit, M., \& Woodside, B. (2003). Hippocampal serotonergic damage induced by MDM A (ecstasy): Effects on spatial learning. Physiology \& Behavior, 79, 281-287. doi:10.1016/S0031-9384(03)00092-1

[24] Vorhees, C. V., Reed, T. M., Skelton, M. R., \& Williams, M. T. (2004). Exp osure to 3,4-methylenedioxy methamphetamin e (MDM A) on postnatal days 11-20 induces reference but not working memory deficits in the Morris water maze in rats: implications of prior learning. International Journal of Developmental Neuroscience, 22, 247-259. doi:10.1016/j.ijd evneu.2004.06.003

[25] Vorhees, C. V., Schaefer, T. L., \& Williams, M. T. (2007). 
Developmental effects of \pm -methylenedioxymethamphetami ne (MDM A) on spatial vs. path integration learning: Effects of dose distribution. Synapse, 61, 488-499.

[26] Vorhees, C. V., Schaefer, T. L., Skelton, M. R., Grace, C. E., Herring, N. R., \& Williams, M. T. (2009). (+/-)3,4-Methylenedioxymethamphetamine (MDMA) dose-dependently impairs spatial learning in the Morris Water Maze after exposure of rats to different five-day intervals from birth to postnatal day twenty. Developmental Neuroscience, 31, 107-120. doi:10.1159/000207499

[27] Fox, H. C., Toplis, A. S., Turner, J. J. D., \& Parrott, A. C (2001). Auditory verbal learning in drug-free ecstasy polydrug users. Human Pharmacology: Clinical Experimental, 16, 613-618. doi:10.1002/hup.344

[28] Heffernan, T. M., Jarvis, H., Rodgers, J., Scholey, A. B., \& Ling, J. (2001). Prospective memory, everyday memory failure and central executive function in recreational users of ecstasy. Human Psychopharmacology, 16, 607-612. doi:10.1002/hup.349

[29] Heffernan, T. M., Ling, J., \& Scholey, A. B. (2001). Subjective ratings of prospective memory deficits in MDMA ('ecstasy') users. Human Psychopharmacology, 16, 339-344. doi:10.1002/hup.290

[30] Wareing M., Fisk J. E., \& Murphy, P. N. (2000). Working memory deficits in current and previous users of MDMA (“ecstasy”). British Journal of Psychology, 91, 181-188. doi:10.1348/000712600161772

[31] Skelton, M. R., Able, J. A., Grace, C. E., Herring, N. R., Schaefer, T. L., Gudelsky, G. A., Vorhees, C. V., \& Williams, M. T. (2008). ( $($ )-3,4-methylenedioxy methamphetamine treatment in adult rats impairs path integration learning: A comparison of single vs once per week treatment for 5 weeks. Neuropharmacology, 55, 1121-1130. doi:10.1016/j.n europha rm.2008.07.006

[32] Battaglia, G., Yeh, S. Y., O’Hearn, E., Molliver, M. E., Kuhar, M. J., \& DeSouza, E. B. (1987). 3,4-M ethylenedioxymetham phetamine and 3,4-methyl $\neg$ enedioxyamphetamine destroy serotonin terminals in rat brain: quantification of neurodegeneration by measurement of [3H]paroxetine-labele d serotonin uptake sites. Journal of Pharmacology and Experimental Therapeutics, 242, 911-916.

[33] Fischer, C., Hatzidimitriou, G., Wlos, J. Katz, \& J., Ricaurte, G. (1995). Reorganization of ascending 5-HT axon projections in animals previously exposed to the recreational drug (+/-)3,4-methylenedioxy methamphetamine (MDMA, 'ecstasy'). Journal of Neuroscience, 15, 5476-5485.

[34] Hatzidimitriou, G., McCann, U. D., \& Ricaurte, G. A. (1999). Altered serotonin innervation patterns in the forebrain of monkeys treated with (+/-)3,4-methylenedioxy methampheta mine seven years previously: Factors influencing abnormal recovery. Journal of Neuroscience, 19, 5096-5107.

[35] Lew, R., Sabol, K. E., Chou, C., Vosmer, G. L., Richards, J., \& Seiden, L. S. (1996). Methylenedioxy methamphetamine-i nduced serotonin deficits are followed by partial recovery over a 52-week period. Part II: radioligand binding and autoradiography studies. Journal of Pharmacology and Experimental Therapeutics, 276, 855-865.

[36] Scanzello, C. R., Hatzdimitriou, G., Martello, A. L., Katz, J. L., \& Ricuarte, G. A. (1993). Response of central serotoner gic neurons to (+)3,4-methylenedioxy methamphetamine (MDMA) injury: Observations in rats. Journal of Pharmacology and Experimental Therapeutics, 264, 14841491.

[37] Shulgin A., \& Carter, M. F. (1980). N,N-Diisopropyltryptam ine (DIPT) and 5-methoxy-N,N-diisopropyltryptamine (5-MeO-DIPT). Two orally active tryptamine analogs with CNS activity. Communications in Psychopharmacology, 4, 363-369.

[38] Ikeda, A., Sekiguchi, K., Fujita, K., Yamadera, H., \& Kog, Y. (2005). 5-methoxy-N,N-diisopropyltryptamine-induced flashbacks. American Journal of Psychiatry, 162, 815. doi:10.1176/appi.ajp.162.4.815

[39] Wilson, J. M., McGeorge, F., Smolinske, S., \& Meatherall, R. (2005). A foxy intoxication. Forensic Science International, 148, 31-36. doi:10.1016/j.forsciint.2004.04.017

[40] United States Drug Enforcement Administration (2003). Schedules of controlled substances: Temporary placement of alpha-methyltryptamine and 5-methoxy-N, N-diisopropyltry ptamine into Schedule I. Final rule. Federal Register, 68(65), 16427-16430.

[41] Compton, D. M., Selinger, M. C., Testa, E. K., \& Larkins, K. D. (2006). An examination of the effects of 5-methoxyN,N-diisopropyltryptamine hydrochloride (Foxy) on cognitive development in rats. Psychological Reports, 98, 651-661.

[42] Compton, D. M., Selinger, M. C., Westman, E., \& Otero, P. (2011). Differentiation of MDMA or 5-MeO-DIPT induced cognitive deficits in rat following adolescent exposure. Psychology \& Neuroscience, 4, 157-169. doi:10.3922/j.psns. 2011.1.018

[43] Skelton, M. R., Schaefer, T. L., Herring, N. R., Grace, C. E., Vorhees, C.V., Williams, M. T. (2009). Comparison of the developmental effects of 5-methoxy-N, N-diisopropyltrypta mine (Foxy) to ( \pm )-3, 4-methylenedisoxymethamphetamine (ecstasy) in rats. Psychopharmacology, 204, 287-297. doi:10.1007/s00213-009-1459-x

[44] Adriani W., \& Laviola, G. (2004). Windows of vulnerability to psychopathology and therap eutic strategy in the adolescent rodent model. Behavioral Pharmacology, 15, 341-352. doi:10.1097/00008877-200409000-00005

[45] Tirelli, E., Laviola, G., \& Adriani, W. (2000). Ontogenesis of behavioral sensitization and conditioned place preference in laboratory rodents. Neuroscience and Biobehavioral Reviews, 23, 163-178. doi:10.1016/S0149-7634(03)00018-6

[46] Spear, L. P. (2000). The adolescent brain and age-related behavioral manifestations. Neuroscience and Biobehavioral Reviews, 24, 417-463. doi:10.1016/S0149-7634(00)00014-2

[47] National Research Council. (1996). Guide for the care and use of laboratory animals. Washington, DC: National Academic Press.

[48] Seago, J. D., Ludvigson, H. W., \& Remley, N. R. (1970). Effects of anosmia on apparent double-alternation in the rat. Journal of Comparative and Physiological Psychology, 71, 435-442. doi:10.1037/h0029116

[49] Paxinos, G., \& Watson, C. (1986). The rat brain in stereotaxic coordinates. San Diego, CA: Academic Press. 
[50] Krettek, J. E., \& Price, J. L. (1977). The cortical projections of the mediodorsal nucleus and adjacent thalamic nuclei in the rat and cat. Journal of Comparative Neurology, 172, 157-192.

[51] Thomas, R. K., Jr., \& Peacock, L. J. (1965). A method of measuring brain lesions. Psychonomic Science, 3, 184.

[52] Chapin, D.S., Lookingland, K.J., \& Moore, K. E. (1994). Effects of LC mobile phase composition on retention times for biogenic amines, and their precursors and metabolites. Current Separations, 7, 68-70.

[53] Winer, B. J., Brown, D. R., \& Michels, K. M (1991). Statistical principles in experimental design (3rd ed.). New York: McGraw-Hill.

[54] Compton, D. M. (1991). Serial learning: A review of the behavioral and physiological research with the rat. Neuroscience and Biobehavioral Reviews, 15, 363-374. doi:10.1016/S0149-7634(05)80029-6

[55] Botwinick. J. (1978). Aging and behavior. New York: Springer.

[56] Gage, F. H., Chen, K. S.,Buzsáki, G., \& Armstrong, D. (1988). Experimental approaches to age-related cognitive impairments. Neurobiology of Aging, 9, 645-655. doi:10.1016/S0197-4580(88)80129-5

[57] Kesner, R. P., \& Churchwell, J. C. (2011). An analysis of rat prefrontal cortex in mediating executive function. Neurobiology of Learning and Memory, 96, 417-431. doi:10.1016/j.nlm.2011.07.002

[58] Muller, M. D., \& Fountain, S. B. (2010). Concurrent cognitive processes in rat serial pattern learning: Item memory, serial position, and pattern structure. Learning and Motivation, 41, 252-272. doi:10.1016/j.lmot.2010.08.003

[59] Nissen, M. J., Knopman, D. S., \& Schacter, D. L. (1987). Neurochemical dissociation of memory systems. Neurology, 37, 789-794. doi:10.1212/WNL.37.5.789

[60] Knopman, D. S., \& Nissen, M. J. (1987). Implicit learning in patients with probable Alzheimer's disease. Neurology, 37, 784-788. doi:10.1212/WNL.37.5.784

[61] Knopman, D. S., \& Nissen, M. J. (1991). Procedural learning is impaired in Huntington's disease: Evidence from the serial reaction time task. Neuropsychologia, 29, 245-254. doi:10.1016/0028-3932(91)90085-M

[62] Kolb, B., \& Wishaw, I. Q. (2009). Fundamentals of human neuropsychology (6th ed.). New York: Worth.

[63] Heindel, W. C., Butters, N., \& Salmon, D. P. (1988). Impaired learning of a motor skill in patients with Huntington's disease. Behavioral Neuroscience, 102, 141-147. doi:10.1037//0735-7044.102.1.141

[64] Willingham, D. B. (1998). A neuropsy chological theory of motor skill learning. Psychological Review, 105, 558-584. doi:10.1037//0033-295X.105.3.558

[65] Fountain, S. B., Rowan, J. D., Kelley, B. M., Wiley, A. R., \& Nolley, E. P. (2008). Adolescent exp osure to nicotine impairs adult serial pattern learning in rats. Experimental Brain Research, 187, 651-656. doi: 10.1007/s00221-008-1346-4

[66] Kesner R. P. (1997). Neurobiological views of memory. In J. L. Martinez \& R. P. Kesner (Eds.), Learning and memory: A biological view pp. 399-438. San Diego, CA: Academic Press.

[67] McDonald R.J., \& White N. M. (1995). Hippocampal and nonhippocampal contributions to place learning in rats. Behavioral Neuroscience, 109, 579-593. doi:10.1037//07357044.109.4.579

[68] Packard, M. G., \& Teather, L. A. (1998). Amygdala modulation of multiple memory systems: Hippocampus and caudate-putamen. Neurobiology of Learning and Memory, 69, 163-203. doi:10.1006/nlme.1997.3815

[69] Salinas, J. A., \& White, N. M. (1998). Contributions of the hippocampus, amy gdala, and dorsal striatum to the response elicited by reward reduction. Behavioral Neuroscience, 112, 812-826. doi:10.1037//0735-7044.112.4.812

[70] Uylings, H. B. M., Groenewegen, H.J., \& Kolb, B. (2003). Do rats have a prefrontal cortex? Behavioural Brain Ressearch, 146, 3-17. doi:10.1016/j.bbr.2003.09.028

[71] Clarke, H. F., Walker, S. C., Crofts, H. S., Dalley, J. W., Robbins, T. W., \& Roberts, A. C. (2005). Prefrontal serotonin depletion affects reversal learning but not attentional set shifting. Journal of Neuroscience, 25, 532-538. doi:10.1523/ JNEUROSCI.3690-04.2005

[72] Clarke, H. F., Dalley, J. W., Crofts, H. S., Robbins, T. W., \& Roberts, A. C. (2004). Cognitive inflexibility after prefrontal serotonin depletion. Science, 304, 878-880. doi:10.1126/science.1094987

[73] Borg, J., Henningsson, S., Saijo, T., Inoue, M., Bah, J., Westberg, L., Lundberg, J., Jovanovic, H., Andree, B., Nordstrom, A. L., Halldin, C., Eriksson, E., \& Farde, L. (2009). Serotonin transporter genotype is associated with cognitive performance but not regional 5-HT1A receptor binding in humans. International Journal of Neuropsychopharmacology, 12, 783-792. doi:10.1017/S1461 145708009759

[74] Piper, B. J., Fraiman, J. B., Owens, C. B., Ali, S. F., \& Meyer, J. S. (2008). Dissociation of the neurochemical and behavioral toxicology of MDMA ('Ecstasy') by Citalopram. Neuropsychopharmacology, 33, 1192-1205. doi:10.1038/sj.n pp.1301491

[75] Skelton, M. R., Williams, M. T., \& Vorhees, C. V. (2006). Treatment with MDM A from P11-20 disrupts spatial learning and path integration learning in adolescent rats but only spatial learning in older rats. Psychopharmacology (Berlin), 189, 307-318. doi:10.1007/s00213-006-0563-4

[76] Compton, D. M., \& Selinger, M. C. (2012). Lifespan neuropsychological assessment of MDMA and 5-MeO-DIPT following exposure during adolescence. Submitted.

[77] Williams, M. T., Herring, N. R., Schaefer, T.L., Skelton, M. R., Campbell, N. G., Lipton, J. W., McCrea, A. E., \& Vorhees, C. V. (2007). Alterations in body temperature, corticosterone, and behavior following the administration of 5-methoxy-diisopropyltryptamine ('Foxy') to adult rats: A new drug of abuse. Neuropsychopharmacology, 32, 1401-1420. doi:10.1038/sj.npp.1301232

[78] Rice D., \& Barone, Jr., S. (2000). Critical periods of vulnerability for the developing nervous system: evidence from humans and animal models. Environmental Health Perspectives, 108(Suppl 3), 511-533. doi:10.1289/ehp.00108 
s3511

[79] Teicher, M. H., \& Andersen, S. L. (1999, October). Limbic serotonin turnover plunges during puberty. In: Poster presented at the Meeting of the Society for Neuroscience, Miami Beach, FL.

[80] Morilak, D. A., \& Ciaranello, R. D. (1993). Ontogeny of 5-hydroxytryptamine2 receptor immunoreactivity in the developing rat brain. Neuroscience, 55, 869-880.

[81] Morley-Fletcher, S., Bianchi, M., Gerra, G., \& Laviola, G. (2002). Acute and carryover effects in mice of MDMA ("ecstasy") administration during periadolescence. European Journal of Pharmacology, 448, 31-38. doi:10.1016/S00142999(02)01904-0

[82] Stone, D. M., Hanson, G. R., \& Gibbs, J. W. (1987). Difference in the central serotonergic effects of methy lenedioxy methamphetamine (MDM A) in mice and rats, Neuropharmacology, 26, 1657-1666.

[83] Fone, K. C. F., Beckett, S. R. G., Topham, I. A., Swettenham, J., Ball, M., \& Maddocks, L. (2002). Long-term changes in social interaction and reward following repeated MDMA administration to adolescent rats without accompanying serotonergic neurotoxicity. Psychopharmacology, 159, 437-444. doi:10.1007/s00213-001-0931-z

[84] Battaglia, G., Yeh, S. Y., \& DeSouza, E. B. (1988). MDM A-induced neurotoxicity: Parameters of degeneration and recovery of brain serotonin neurons. Pharmacology, Biochemistry, and Behavior, 29, 269-274. doi:10.1016/00913057(88)90155-4

[85] Steele, T. D., Nichols, D. E., \& Yim, G. K. (1989). MDMA transiently alters biogenic amines and metabolites in mouse brain and heart. Pharmacology, Biochemistry, and Behavior, 34, 223-227. doi:10.1016/0091-3057(89)90303-1

[86] Wang, X., Baumann, M.H., Xu, H., Morales, M., \& Rothman, R. B. (2005). (+)-3,4-Methylenedioxymethamphetamine administration to rats does not decrease levels of the serotonin transp orterprotein or alter its distribution between endosomes and the plasma membrane. Journal of Pharmacology and
Experimental Therapeutics, 314, 1002-1012. doi:10.1124/ jpet.105.088476

[87] Wang, X., Baumann, M. H., Xu, H., \& Rothman, R. B. (2004). 3,4-methylenedio xy methamphetamine (MDMA) administrat ion to rats decreases brain tissue serotonin but not serotonin transp orter protein and glial fibrillary acidic protein. Synapse 53, 240-248. doi:10.1002/syn.20058

[88] O’Callaghan, J. P., \& Miller, D. B. (1993). Quantification of reactive gliosis as an approach to neurotoxicity assessment. NIDA Research Monographs, 136, 188-212.

[89] Olivier, J., Cools, A., Ellenbroek, B., Cuppen, E., \& Homberg, J. (2010). The serotonin transporter knockout rat: A review. In A. V. Kalueff \& J. L. LaPorte (Eds.), Experimental models in serotonin transporter research pp. 170-213. Cambridge, UK: Cambridge University Press.

[90] Parrott, A. C. (2002). Recreational Ecstasy/MDMA, the serotonin syndrome, and serotonergic neurotoxicity. Pharmacology, Biochemistry, and Behavior, 71, 837-844. doi:10.1016/S0091-3057(01)00711-0

[91] Drugs-Forum (2012). Retrieved July 12, 2012, from http://www.drugs-forum.com/forum/index.php

[92] My sister has been using cocaine \& ecstasy. (2012). Retrieved July 12, 2012, from http://www.thegooddrugs guide.com/ecst asy/faq.htm\#13

[93] Nakagawa, T., \& Kaneko, S. (2008). Neuropsy chotoxicity of abused drugs: Molecular and neural mechanisms of neuropsychotoxicity induced by methamphetamine, 3,4-methylenedioxymethamphetamine (Ecstasy), and 5methoxy-N,N-diisopropyltryptamine (Foxy). Journal of Pharmacological Sciences, 106, 2-8. doi:10.1254/jphs.FM00 70141

[94] Green, A. R., Mechan, A. O., Elliott, J. M., O’Shea, E., \& Colado, M. I. (2003). The pharmacology and clinical pharmacology of 3,4-methylenedioxymethamphetamine (MDM A, “ecstasy”). Pharmacological Reviews, 55, 463-508. doi:10.1124/pr.55.3.3 